\title{
Multivariate modeling of retaining walls
}

\author{
Vladimir A. Dmitrienko ${ }^{1}$, Irina A. Kapralova ${ }^{1}$, Valeria V. Baklakova ${ }^{1 *}$, Aleksei G. Iliev ${ }^{1}$, \\ and Nataliya $V$. Merenkova ${ }^{1}$ \\ ${ }^{1}$ Institute of service and business(branch) of Don state technical University, 147 Shevchenko, 346500, \\ Rostov region, Shakhty, Russia
}

\begin{abstract}
When designing a parking lot of limited size with a large elevation difference, a decision to construct an earth embankment with a retaining wall was made. Based on the analysis of the results of engineering geological surveys and construction conditions, four options of constructing a retaining wall were considered. The stress-strain states of the protective structures and embankments were studied in details with the help of finite element modeling in order to select the optimal technical solutions for retaining walls. Based on the analysis of the distribution of stresses and strains in the structures, the advantages and disadvantages of each option are determined. The optimal combined version of constructing a thin retaining wall with unloading screens and hardening of the embankment by means of anchorinjectors is substantiated.
\end{abstract}

\section{Introduction}

In modern conditions, the problem of free territories appropriate for building even in regional towns remains very relevant. Therefore, auxiliary facilities are increasingly to be located in areas that are rather complicated from a construction point of view, and under strict observance of environmental safety measures [1].

To organize a parking lot near facility under construction in town Shakhty, a site was required, but the specifics of the relief and the dense area development made it difficult. It was a territory free of building with a width of $23.5 \mathrm{~m}$ limited by the embankment of the road and the security zone of the main gas pipeline.

The elevation difference from the ground to the level of the road is $8.5 \mathrm{~m}$. Obtaining the required parking area, taking into account the security zone of the gas pipeline, is possible only with the construction of a retaining wall on the east side of the construction site.

\section{Materials and Methods}

When selecting options for the construction design of retaining walls for earth embankments, massive, angular and thin retaining walls, having the greatest distribution, were considered [2-3]. Taking into account various characteristics of the foundation soils, embankments and concrete structures, as well as the complex stress-strain states (CSSS) of elements, the studies of various options for reinforcing structures were carried out by means of finite element

\footnotetext{
${ }^{*}$ Corresponding author: valeriya.baclackowa@yandex.ru
} 
modeling (FEM) [4-8]. From the point of view of technology, the simplest option is to use a massive wall. However, the calculations showed that for the device design of the required size [3], providing the required ratio of active pressure of the embankment and the design resistance of the soil, the volume of concreting will be $813 \mathrm{~m}^{3}$. In addition, the analysis of the deformation scheme (Fig. 1) shows that due to the low mechanical characteristics of the soil at the base of the embankment, the sediment of the leading edge of the foundation wall reaches $256 \mathrm{~mm}$, even without taking into account the load from cars, and the deviation of the top wall from the vertical can make up 1.66 meters

Deformed Mosh

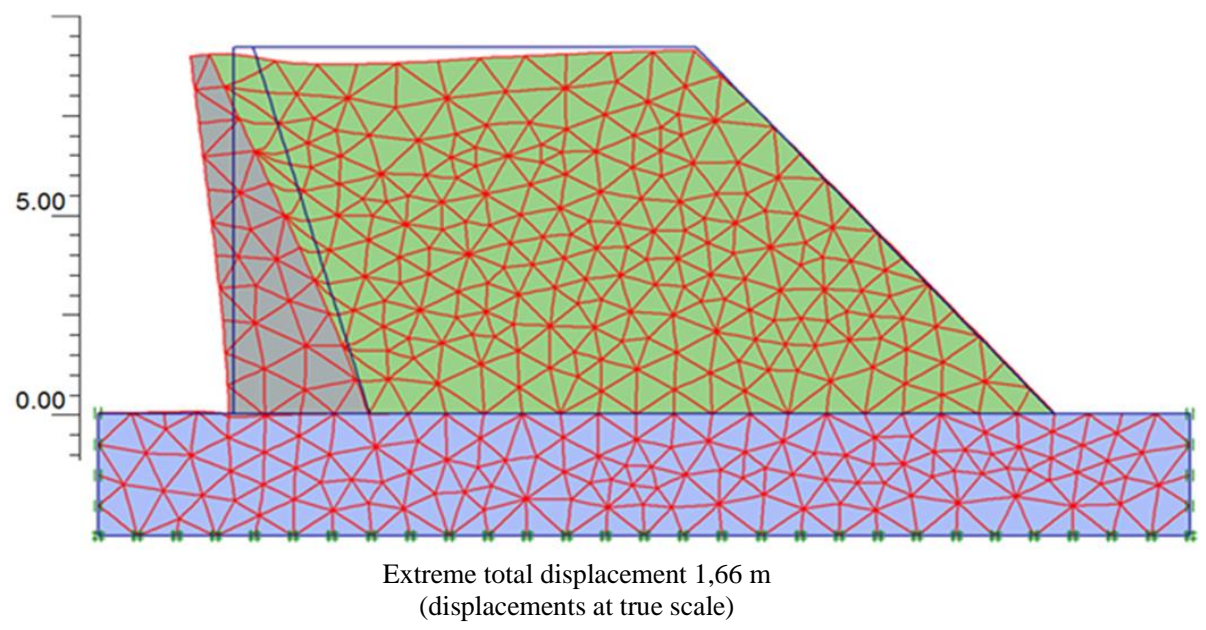

Fig. 1. Deformation scheme of construction

Concreting can be reduced by about a third by replacing a massive wall with an angled one. Calculations in determining the size of the structure showed that the design resistance of the soil under the base of the foundation wall is $211.3 \mathrm{kPa}$, and the active pressure of the foundation on the foundation soil is $733.4 \mathrm{kPa}$, that is, the stresses are more than 3 times higher than the calculated ones. Therefore, it is necessary to significantly increase the basement area to reduce the effectiveness of the corner wall. The nature of the deformation of the base and wall is shown in Figure 2.

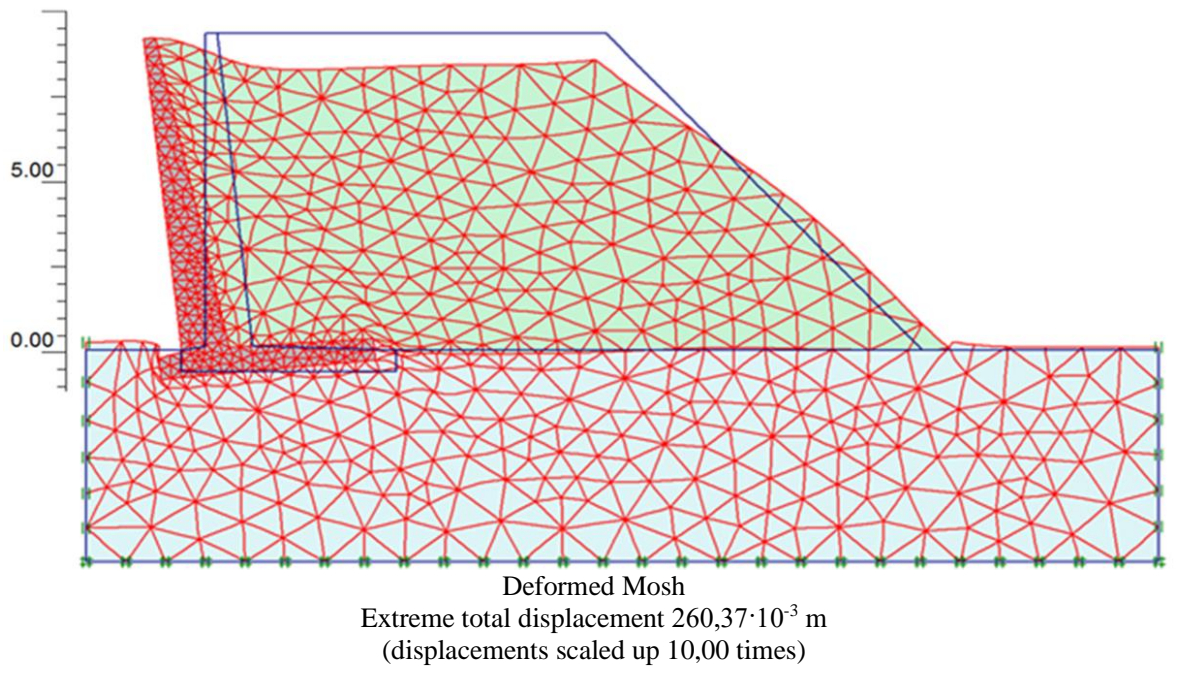

Fig. 2. The deformation scheme of structures and soil base 
The analysis of the region of limiting deformations in the circuit elements of its own weight (Fig. 3) and the load from vehicles (Fig. 4) indicate the formation of plastic flow zones in the embankment and under the front edge of the wall foundation. This will lead to deformations and, accordingly, to soil removal in the security zone of the gas pipeline.

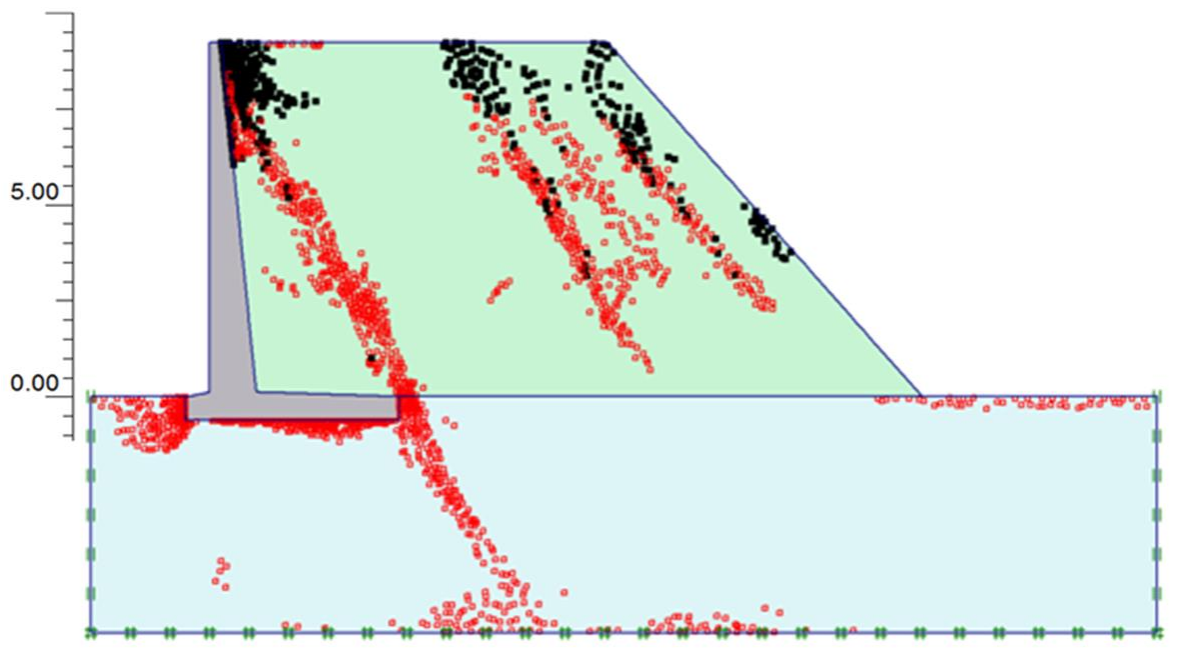

Fig. 3. Areas of ultimate deformations of structures and soil foundation

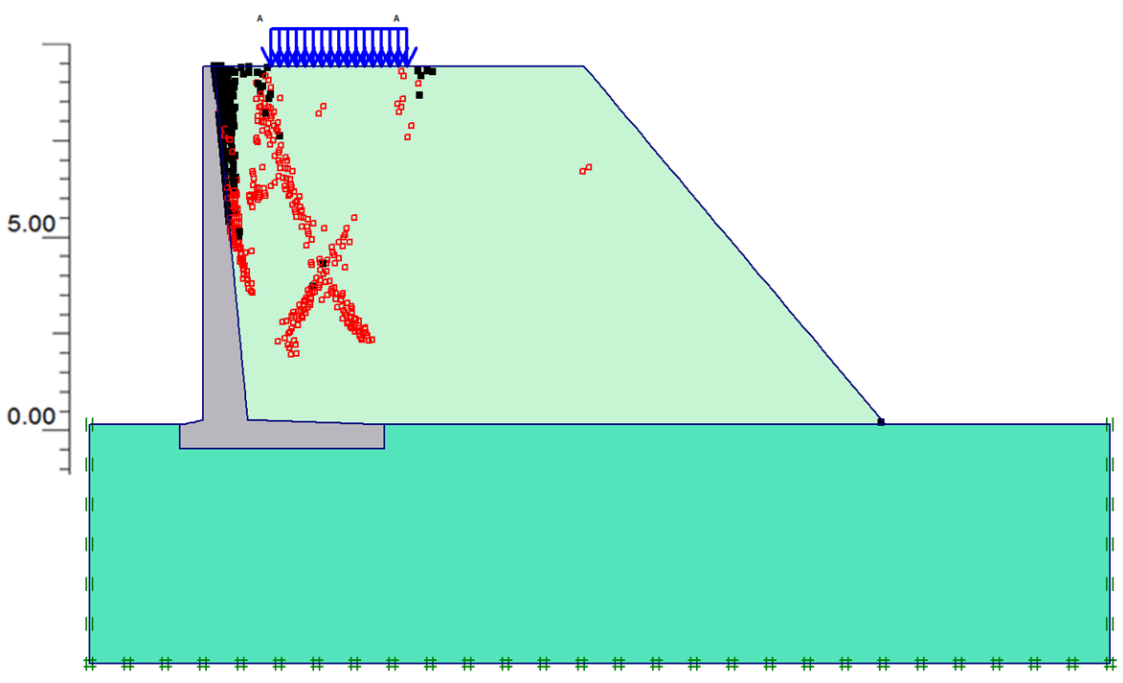

Fig. 4. The formation of plastic deformations from the weight of vehicles

\section{Results}

In our opinion, the most realistic way out of this situation is to use a thin retaining wall, and to reduce the stresses on its back side and on the surface of the embankment, it is necessary to form a reinforced zone in the embankment.

Since the load on the retaining wall is formed due to the formation of a creeping prism (Fig. 5), the parameters of which are determined by the height of the embankment, the characteristics of the soil and the weight of the vehicles, it is possible to solve this problem by using the bearing ability of fillings. 


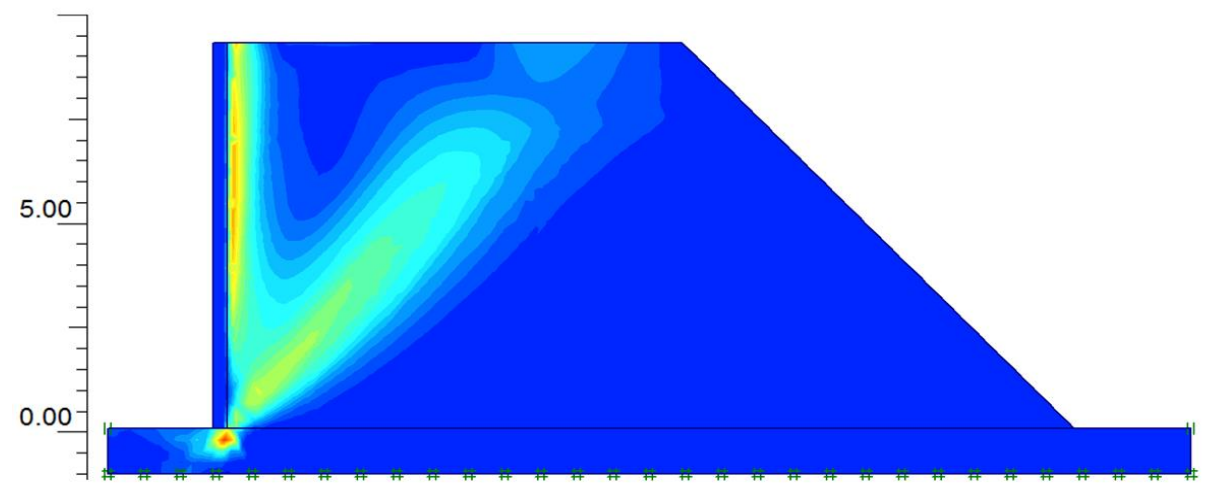

Fig. 5. Forming a creeping prism

The first option is layer-by-layer anchoring of the vertical wall with reinforcement nets with their fixing in the backfill with cement (Fig. 6).

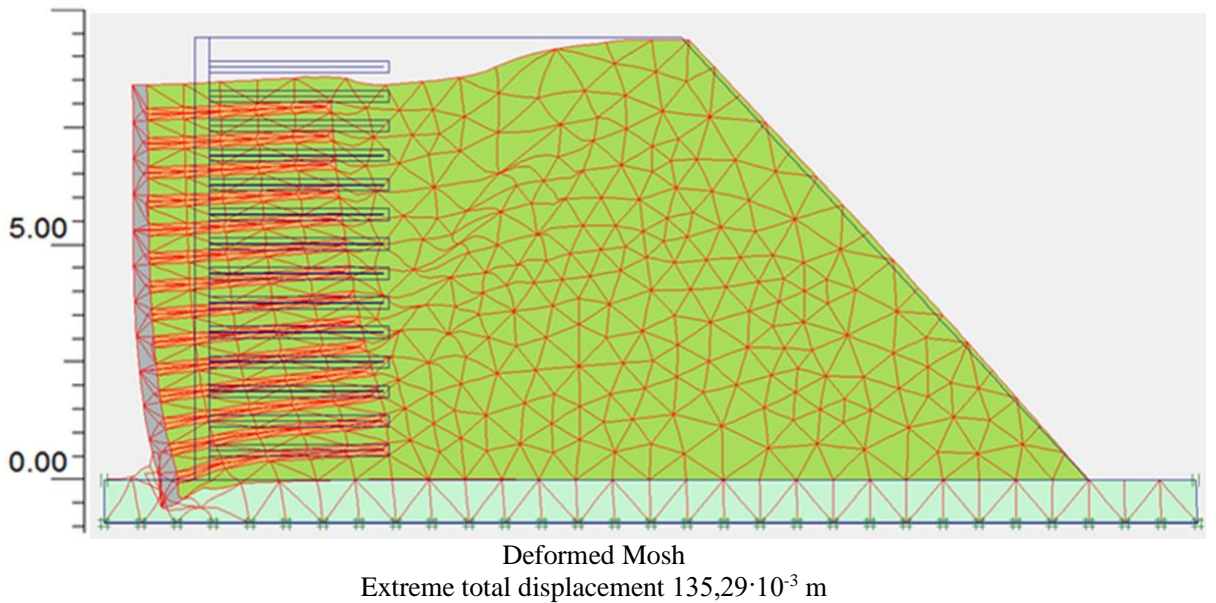

Fig. 6. Distribution of movements of the embankment and retaining wall during reinforcement with reinforcement meshes

The second option is to fix a thin wall with pipes for the formation of a root in bulk soil outside the creeping prism. The sequence of works on the construction of the facility is as follows. Wall concreting is performed in vertically moving formwork. As they being laid in concrete, holes are made for the passage of perforated pipes. When concrete reaches $60 \%$ of the project strength, the soil is filled in layers of thickness $0.2-0.3 \mathrm{~m}$ and is compacted. When reaching the level of compacted soil holes, pipes are laid on the ground and are passed through the holes to the outer surface of the wall being erected, where the supporting plates are welded to them. Then, the next layer of soil is laid and fixed by pumping the injection compound into the embankment through pipes, which after hardening will act as anchors, and the whole layer, after compaction and hardening, acts as a screen.

Distribution of deformations in structures when fastened with anchors are shown in Figure 7.

The results of the simulation of the first two options used for the construction of a retaining wall show that even without taking into account the weight of cars, the stresses under the front edge of the foundation are more than two times higher than permissible bases for soil. Besides, the slope angle of the embankment should not exceed $35^{\circ}$. In this case, the 
length of the retaining embankment will be $54 \mathrm{~m}$, and the width of the wall along the lower base is $26 \mathrm{~m}$, which means that the contour of the embankment will overlap the border of the allotted section. Thus, even preliminary calculations exclude the possibility of using the first two options.

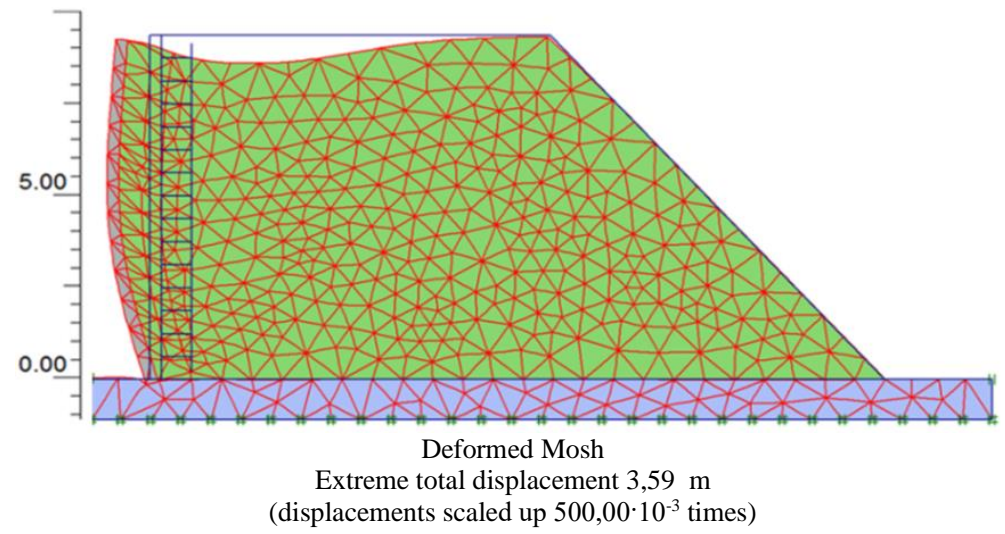

Fig. 7. Full displacements of an array reinforced with anchors (step $0.5 \mathrm{~m}$ in height)

When modeling a thin retaining wall with anchors fixed in the bottom of the well, there is a decrease in deformations of the structures, but there is a flattening of stress isoplasts in the embankment (Fig. 8), which will require a reduction in the slope angles, which is unacceptable.

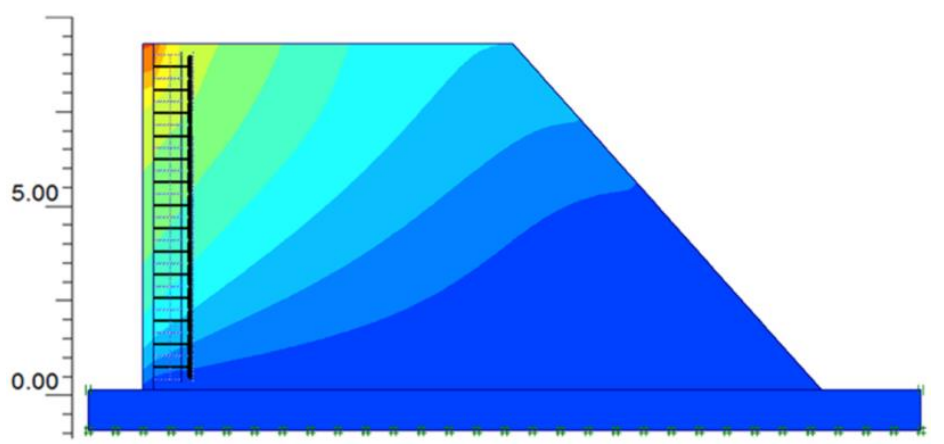

Fig. 8. Isopole stresses in the embankment at securing the anchors in the bottom of the well

Since the fourth version of constructing a protective structure with unloading screens also has some drawbacks, the combined scheme is considered to strengthen the embankment and strengthen a thin wall with screens made of reinforcing mesh and perforated steel pipes through which the hardening solution is injected into the embankment. Analysis of the simulation results (Fig. 9) shows that in this case, in addition to reducing stresses and deformations in structures, the angle of the slip plane of the sliding prism significantly increases. So, it is possible to increase the slope angle of the embankment in the hardening zone.

In addition, the zone of maximum deformations is shifted from the wall into the embankment (Fig. 10), which will allow optimizing the hardening parameters by redistributing the stresses at the base of the embankment and minimizing the costs for strengthening of the soil. 


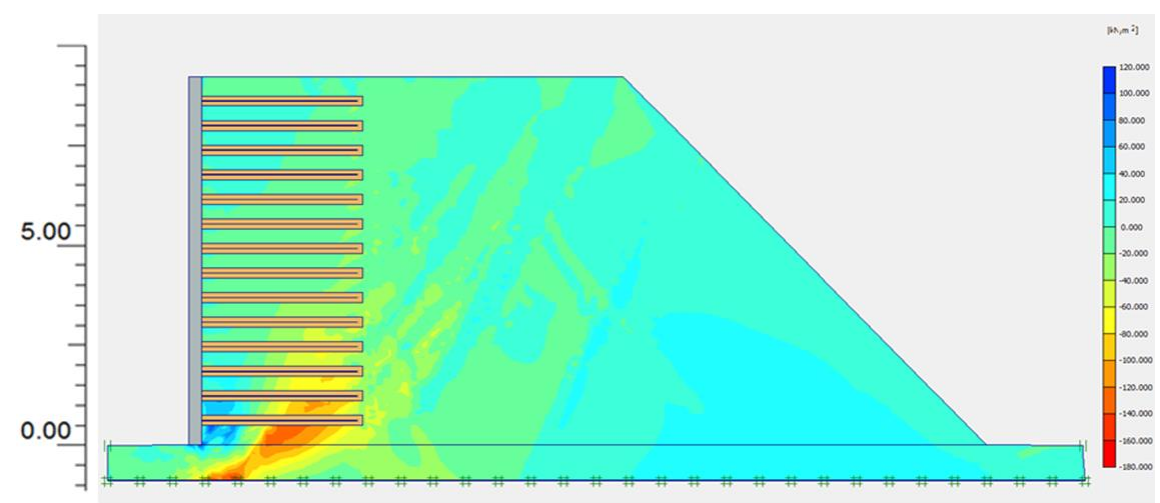

Fig. 9. The distribution of tangential stresses in the embankment at reinforcing mesh reinforcement and anchor injectors

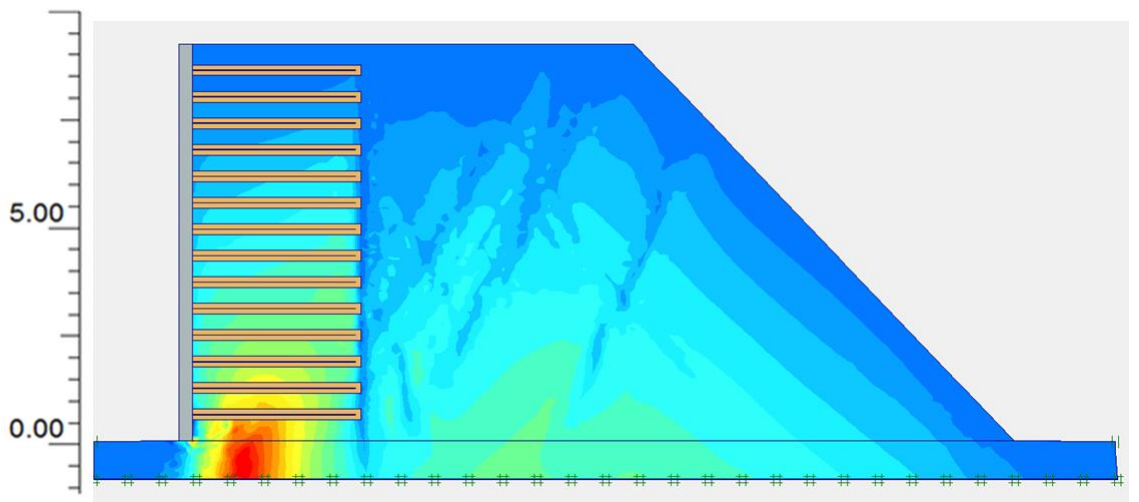

Fig. 10. Formation of displacement zones in the embankment at reinforcing mesh reinforcement and anchor injectors

The proposed construction option will reduce the amount of concreting, reduce the size of the embankment and prevent the embankment from crossing the boundaries of the designated area.

To reduce the cost of injection work solutions of small fractions of waste of crushing slag metallurgical plant can be used, not only in the form of fillers but also as active mineral additives [9-11].

The conducted studies show that mathematical methods for modeling complex construction objects allow, with minimal effort, to substantiate multivariate design solutions at the stage of pre-design developments.

\section{Conclusion}

1. Before the implementation of the project and feasibility of the study of the proposed options for the construction of a retaining wall, it is necessary to carry out engineering and geological surveys in the construction area of the soil embankment.

2. For the construction of a retaining wall it is possible to use four options:

- erection of a massive wall (characterized by simple technology of the device, but the material and labor costs are very high), the volume of concreting is $813 \mathrm{~m}^{3}$, the construction of formwork $182 \mathrm{~m}^{2}$;

- erection of the corner wall (the volume of concreting is reduced by - $440 \mathrm{~m}^{3}$, however, 
the formwork must be arranged on both sides of the wall $-390 \mathrm{~m}^{2}$, reinforcement (approximately 55 tons) and the device of counter forts will significantly increase labor costs);

- erection of a thin retaining wall with discharge screens, the wall and screens are erected as the embankment is installed, the concreting volume is $90 \mathrm{~m}^{3}$, the erection of the formwork is $363 \mathrm{~m}^{2}$, reinforcement with nets and individual rods is 20 tons, the arrangement of screens made of mesh and fine concrete is $132 \mathrm{~m}^{3}$;

- erection of a thin retaining wall with anchors, an anchor made of perforated pipes $4 \div$ $12 \mathrm{~m} \varnothing 40 \mathrm{~mm}$ in length are laid in layers simultaneously with an embankment, concreting volume is $90 \mathrm{~m}^{3}$, erection of formwork $363 \mathrm{~m}^{2}$, reinforcement with nets and individual rods $20 \mathrm{t}$, anchor injectors $126 \mathrm{pcs} \mathrm{m}$ of pipes), fastening of anchors - discharge of $31.5 \mathrm{~m}^{3}$ of cement.

3. The fourth option requires several high costs, but provides a higher reliability of structures, and therefore it can be recommended for use.

The research was carried out in the framework of the state task 7.9213.2017 / BCh "Development of methods and means of construction and maintenance of underground and deep structures".

\section{References}

1. M.D. Molev, I.A. Zanina, N.I. Stuzhenko, Inzhenernyj vestnik Dona 4. (2013)

2. Russian State Standard SNiP 2.09.03-85

3. V.A. Il'ichev, V.I. Krutov, Osnovaniya, fundamenty, podzemnye sooruzheniya (Moscow, Srojizdat, 1985)

4. O. Rahmani, S. Kebdani, Introduction a la metode des elements finis pour les ingeneurs. (O.P.U. Alger, 1981)

5. R.D. Cook, D.S. Malcus, M.E. Plecha, Concept and applications of finite element analylis. (University of Wisconsin-Madison, 1989)

6. A.Yu. Prokopov, V.F. Akopyan, K.N. Gaptlislamova, Inzhenernyy vestnik Dona. 4. (2013)

7. A.M. Pavlenko, Gornyy informatsionno-analiticheskiy byulleten, 9, 170-173 (2008)

8. N. Chernysheva, L. Rozin MATEC Web of Conferences, 53, (2016) doi.org/10.1051/matecconf/20165301042

9. V.I. Golik, Yu.I. Razorenov, Tekhnologii betonov, 9-10 (134135). 44-47 (2017)

10. V.I. Golik, A.N. Doolin, M.A. Komissarova, R.A. Doolin, International Business Management. 9. 6. 1119-1123 (2015)

11. A.Yu.Prokopov, S.A. Maslennikov, O. V. Bazavova, Nauchnoe obozrenie, 9, 758-761 (2014) 